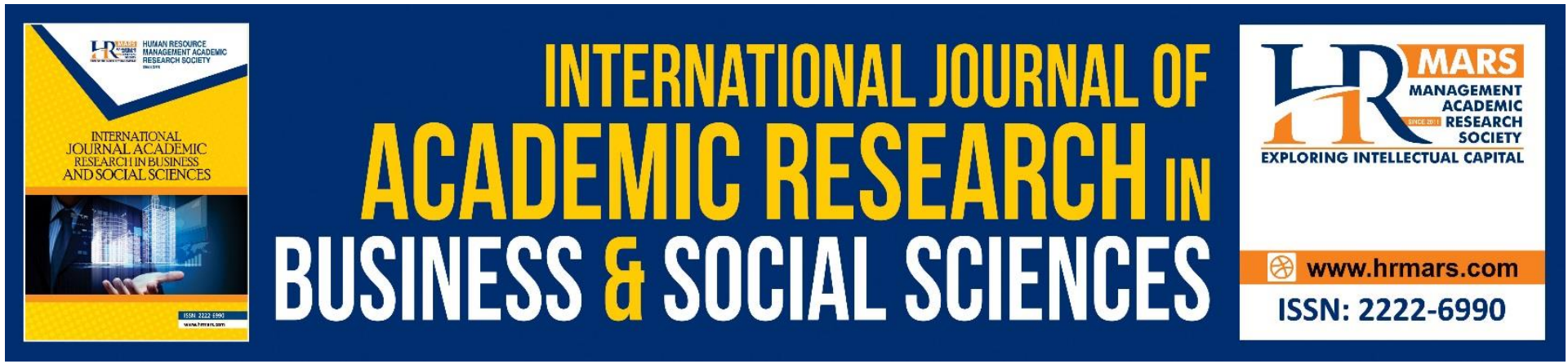

\title{
Usability of Multicultural Counseling Self-Efficacy-Racial Diverse (Mcse-Rd) on The Sample of Malaysian Undergraduate Counselor Trainees
}

Maizatul Mardiana Harun, Wan Marzuki Wan Jaafar, Asmah Ismail

To Link this Article: http://dx.doi.org/10.6007/IJARBSS/v10-i12/8043

DOI:10.6007/IJARBSS/v10-i12/8043

Received: 18 October 2020, Revised: 16 November 2020, Accepted: 29 November 2020

Published Online: 23 December 2020

In-Text Citation: (Harun et al., 2020)

To Cite this Article: Harun, M. M., Jaafar, W. M. W., \& Ismail, A. (2020). Usability of Multicultural Counseling Self-Efficacy-Racial Diverse (Mcse-Rd) on The Sample of Malaysian Undergraduate Counselor Trainees. International Journal of Academic Research in Business and Social Sciences, 10(12), 597-612.

Copyright: @ 2020 The Author(s)

Published by Human Resource Management Academic Research Society (www.hrmars.com)

This article is published under the Creative Commons Attribution (CC BY 4.0) license. Anyone may reproduce, distribute, translate and create derivative works of this article (for both commercial and non-commercial purposes), subject to full attribution to the original publication and authors. The full terms of this license may be seen at: http://creativecommons.org/licences/by/4.0/legalcode

Vol. 10, No. 12, 2020, Pg. 597 - 612

http://hrmars.com/index.php/pages/detail/IJARBSS

JOURNAL HOMEPAGE

Full Terms \& Conditions of access and use can be found at http://hrmars.com/index.php/pages/detail/publication-ethics 


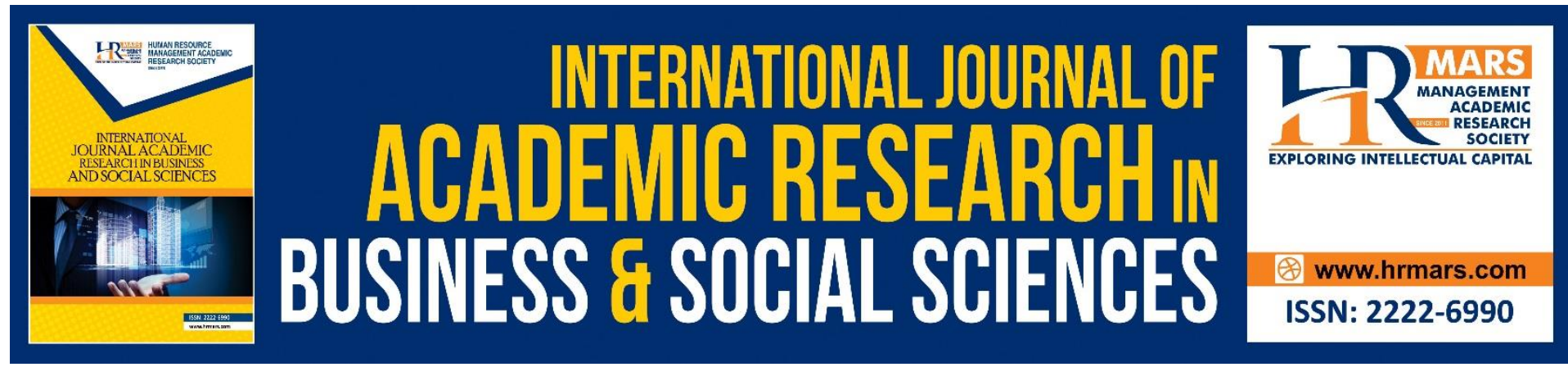

\title{
Usability of Multicultural Counseling Self- Efficacy-Racial Diverse (Mcse-Rd) on The Sample of Malaysian Undergraduate Counselor Trainees
}

\author{
Maizatul Mardiana Harun, Wan Marzuki Wan Jaafar, Asmah \\ Ismail \\ Universiti Putra Malaysia
}

\begin{abstract}
Based on Self-Efficacy Theory, multicultural counseling self-efficacy is derived from the selfefficacy concept. It is usually measured together when measuring multicultural counseling competence. This study aims to examine the usability of Multicultural Counseling SelfEfficacy- Racial Diverse (MCSE-RD) on the sample of undergraduate counselor trainees in the Malaysian context. The usability is measured through investigating the adapted and Malay translated MCSE-RD psychometric properties such as its factor structure, reliability and validity. There are 205 counselor trainees from local universities who completed the questionnaire. The factor analysis resulted in the adapted MCSE-RD's three-factor structure with 16 items were confirmed. Findings showed that MCSE-RD possessed excellent reliability as the internal consistency was $\alpha=.966$ and construct reliability of .938. For construct validity, the values of the MCSE-RD's items were in the range of $r=.681$ to .870 . The convergent validity value obtained the confirmatory factor analysis was .836 . As the factor structure, reliability, and validity were all confirmed, the usability of the Malay translated MCSE-RD was also warranted. Moreover, its high reliability and good validity resulted that MCSE-RD can successfully be used by counselor trainees across gender and ethnicity. (185 words)
\end{abstract}

Keywords: Multicultural Counseling Self-Efficacy, Counselor Trainees, Psychometric Properties, Reliability, Validity

\section{Introduction}

In his Self-Efficacy Theory, Bandura $(1977,1982)$ defines self-efficacy as individuals' level of confidence in performing a task or behavior to achieve specific goals. He also maintained that self-efficacy needs to be measured specifically as general self-efficacy unable to reflect precisely one's confidence. The self-efficacy had gained ample attention from researchers in education as well as researchers in counseling. The term counseling self-efficacy was coined by Larson and Daniels (1998) and it was described as "one's beliefs or judgments about her or his capabilities to effectively counsel a client in the near future" (p. 180). One of the extensive works on self-efficacy in counseling research was done by Larson and Daniels (1998) where they published a 15 years review involving 32 studies (around 1983 to 1998). Most of the reviewed studies found that self-efficacy influenced counselors' competencies. 
There is quite a number of measures for counseling self-efficacy where Counseling SelfEstimate Inventory (COSE; Larson et al., 1992) and Self-Efficacy Item (SEI; Sipps et al., 1988) were mentioned as the two most used by the researchers (Larson \& Daniels, 1998). In the context of Malaysia, COSE is also frequently used by researchers in measuring counselors' counseling self-efficacy. For instance, Wan Jaafar et al. (2009), Ooi (2016), and Mazila Ghazali (2017) utilized COSE in their study. Other than COSE and SEI, there are other counseling selfefficacy measures such as School Counselor Self-Efficacy Scale (SCSE; Bodenhorn \& Skagss, 2005), and Counselor Activity Self-Efficacy Scales (CASES; Lent et al., 2003). For further information on other counseling self-efficacy measures, please refer to the review paper by Larson and Daniels (1998).

Multicultural counseling self-efficacy is defined as "counselors' confidence in their ability to perform a set of multicultural counseling skills and behaviors successfully" (p. 491, Constantine \& Ladany, 2001). In 2005, the Multicultural Counseling Self-Efficacy-Racial Diverse (MCSE-RD) was developed by Sheu to specifically measure the skills part of multicultural counseling competence which most existing multicultural counseling competence measures are unable to do so. He also attempted to measure multicultural counseling self-efficacy in the means to find a clarification on the counselors' situation of "know what to do" but having doubt about "how to do" in counseling with multicultural clients. In addition, Sheu and Lent (2007) maintained that the purpose of MCSE-RD was to measure self-perceived capability or confidence to counsel racially clients who are racially diverse. The MCSE-RD comprises 37 items from three subscales that are Multicultural Intervention (24 items), Multicultural Assessment (6 items), and Multicultural Counseling Session Management ( 7 items). Sheu (2005) obtained $\alpha$ of .79 for full scale and $\alpha$ ranging from .60 to .78 for its subscales (Multicultural Intervention $=.77$, Multicultural Assessment $=.60$, Multicultural Counseling Session Management $=.78$ ).

Other existing instruments that specifically measure multicultural counseling self-efficacy is the School Counselor Multicultural Self-Efficacy Scale (SCMES). The SCMES was developed by Holcomb-McCoy et al. (2008) to specifically measure the school counselors' self-belief in their ability to carry out and perform relevant tasks while working with ethnically and culturally diverse school students. The total number of items in SCMES is 52 items that build up the six subscales, (i) Knowledge of Multicultural Counseling Concepts (14 items), (ii) Using Data and Understanding Systemic Change (9 items), (iii) Developing Cross-Cultural Relationships (7 items), (iv) Multicultural Awareness (9 items), (v) Multicultural Assessment (7 items), and (vi) Applying Racial Concepts to Practice (6 items). The reliability of total SCMES is high with alpha of .93 and also high for respective subscales (Knowledge of Multicultural Counseling Concepts $=.95$, Using Data and Understanding Systemic Change $=.91$, Developing Cross-Cultural Relationships $=.89$, Multicultural Awareness $=.93$, Multicultural Assessment $=.89$, and Applying Racial Concepts to Practice $=.88$ ).

Despite higher reliability coefficients, the MCSE-RD is a choice for the study as its ability to tap the skills component of multicultural counseling competence. In fact, a number of studies reported higher value of reliability coefficients of MCSE-RD. Harun et al. (2014) stated the high reliability coefficients of MCSE-RD full scale $(\alpha=.99)$ and subscales (Multicultural Intervention $=.96$; Multicultural Assessment $=.93$; Multicultural Counseling Session Management $=.94)$. These were reported by a team of researchers who conducted team translation and adapted MCSE-RD for school counselors. Barden and Greene (2015) also 
reported high reliability coefficients where $\alpha=.94$ for full-scale, .89 for Multicultural Intervention, .87 for Multicultural Assessment, and .95 for Multicultural Counseling Session Management.

The MCSE-RD was chosen to undergo back-to-back translation and expert validation process because of its operational definitions paralleled with this study conceptual and operational definition of multicultural counseling self-efficacy in. Moreover, considering the counselor trainees as the respondents, MCSE-RD is the right choice as it was tested on counselor trainees. Therefore, to make sure that MCSE-RD will be able to provide precise findings of undergraduate counselor trainees' multicultural counseling self-efficacy level, its usability needs to be investigated. Generally, this study aims to examine the usability of multicultural counseling self-efficacy on the sample of undergraduate counselor trainees. The specific aims of this study were to: (1) confirm the factor structure of translated MCSE-RD, (2) evaluate the reliability of translated MCSE-RD, and (3) investigate the validity of MCSE-RD.

\section{Methods}

\section{Participants}

The 208 trainees were selected through probability random sampling. During the study, the selected counselor trainees were at the end of their counseling internship training in various organizations in Klang Valley and East Malaysia. There were 205 trainees who successfully responded to the questionnaire. The distribution of respondents in term of age, gender, ethnicity, and religion are majored by respondents whose age are between 22 to 24 years old ( $n=161,78.5 \%)$, female $(n=161,78.5 \%)$, Malay $(n=157,76.6 \%)$, and Muslim $(n=170$, 82.9\%). Table 1 presents a detailed description of the sample.

Table 1. Distribution of respondent's demographic

\begin{tabular}{llll}
\hline $\begin{array}{l}\text { Demographic } \\
\text { variables }\end{array}$ & Categories & Frequency & Percentage \\
\hline \multirow{2}{*}{ Age } & $22-24$ & 161 & 78.5 \\
& $25-27$ & 38 & 18.5 \\
& $28-30$ & 6 & 2.9 \\
\hline \multirow{2}{*}{ Gender } & Male & 44 & 21.5 \\
& Female & 161 & 78.5 \\
\hline \multirow{2}{*}{ Ethnicity } & Malay & 157 & 76.6 \\
& Non-Malay & 48 & 23.4 \\
\hline \multirow{2}{*}{ Religion } & Muslim & 170 & 82.9 \\
& Non - Muslim & 35 & 17.1 \\
\hline
\end{tabular}

\section{Instruments}

The instrument used in the data collection is the adapted and translated MCSE-RD. Sheu (2005) first developed the MCSE-RD to assess counselors' multicultural counseling selfefficacy that specifically designed to measure the skill component of multicultural counseling competence. The MCSE-RD comprised of 37 items that belong to three subscales; (i) multicultural intervention (24 items), (ii) multicultural assessment (6 items), and (iii) multicultural counseling session management ( 7 items). All of the items were positively 
stated. The items were scored on a scale ranging from 0 (no confidence at all) to 9 (complete confidence). The MCSE-RD's total score (ranging from 0 - 333) reflects the level of multicultural counseling self-efficacy and higher score indicates greater confidence in one's ability to successfully execute a set of multicultural counseling skills and behaviors.

The MCSE-RD were reported to have high reliability that ranging from .92 to .98 for MCSE-RD subscales and .98 for the total MCSE-RD (Sheu \& Lent, 2007). It was also reported that MCSE$\mathrm{RD}$ had good discriminant validity that were supported by small and nonsignificant correlations between MCSE-RD and social desirability (Sheu, 2005). Barden and Greene (2015) who tested the MCSE-RD involving counselor trainees did report a satisfying value of reliability and validity of the instruments. In their study, the Cronbach's alpha coefficient for full-scale was .94 and ranged from .89 and .95 for the subscales. In addition, Rusnani and Yusof (2017) also reported high reliability $(\alpha=.98)$ and good validity $(r=.88)$ of MCSE-RD on the sample of secondary school counseling teacher. Therefore, based on the convincing reported reliability and validity, MCSE-RD is a prominent instrument in measuring counselor trainees' multicultural counseling self-efficacy.

Data on respondent's age, gender, ethnicity, and religion were obtained through a demographic sheet that was attached at the last page of the questionnaire.

\section{Procedure}

Firstly, permission to translate and adapt the instrument was asked and granted by the MCSERD's original author. In this study, a back-to-back translation method was used to produce the Malay version of MCSE-RD. The appointed translators are all experts in counseling and have high proficiency in English. The translated draft of MCSE-RD undergoes the pre-testing process to gain feedback on the term, phrase, and structure sentence used.

After a few corrections made on some spelling errors, the pre-tested draft is now ready for the content validation process. The process was completed by five counselling experts whose interest is on multicultural counseling in their teaching and research. The instrument was piloted on 73 counsellor trainees prior to the actual data collection process. Then, in the actual data collection process, another 208 counsellor trainees who were recruited through cluster random sampling. This study consumed four weeks duration to be accomplished. As a result, a total of 205 questionnaires were returned and 200 were analyzed.

\section{Exploratory Factor Analysis (EFA)}

The exploratory factor analysis (EFA) is a method in which data is analyzed and information is generated on the numbers of factors needed to represent the data during the early stages of research. In this study, the principal component analysis (PCA) was used and conducted using data from pilot study. The MCSE-RD had fulfilled the requirement for the implementation of PCA based on the Bartlett test of Sphericity and the Kaiser Mayer Olkin results. The PCA determines the factors which account for the particular construct 's total variance. The factor analysis resulted in a 3-factor with eigenvalues above 1.0. which accounted for $75.21 \%$ of the total variance. While, Hair et al. (2019) and Stevens (2009) recommend .40 as acceptably lowest loading in factors analysis that can be included in the scale. However, results indicate that factor loadings for 15 items were less than the recommended cut-off point. Thus, Table 
2 presents the distribution of the 22 items after factor analysis with factor loadings range from .519 to .846 , which are sufficient and acceptable.

Table 2. The 3-factor structure and distribution of 22 items

\begin{tabular}{llll}
\hline Item & 1 & 2 & 3 \\
\hline mcse3 & & .761 & .746 \\
mcse4 & & .708 & \\
mcse5 & & .792 & \\
mcse6 & & .659 & \\
mcse7 & & .846 & \\
mcse8 & & .748 & .694 \\
mcse9 & & .768 & .748 \\
mcse10 & & .759 & .591 \\
mcse11 & .779 & .519 \\
mcse12 & & & \\
mcse13 & & & \\
mcse14 & & & \\
mcse18 & & & \\
mcse19 & & & \\
mcse24 & & & \\
mcse25 & .685 & & \\
mcse26 & .712 & & \\
mcse28 & .718 & & \\
mcse29 & .747 & & \\
mcse31 & .763 & & \\
mcse32 & .640 & & \\
mcse35 & .755 & & \\
\hline
\end{tabular}

\section{Statistical Analysis}

The 200 usable responses from actual data collection were analyzed using SPSS 25 and AMOS 23 computer program. The hypothesized factor structure model was tested by confirmatory factor analysis (CFA). The Goodness of Fit Indexes (GFI), the comparative fit index (CFI), the incremental fit indexes (IFI), and the Root Mean Square Error of Approximation (RMSEA) are the four common fit indexes used to determine model fit (McDonald \& Ho, 2002). Hair et al. (2019) maintained that a model shall fulfil the requirement of at least three fit indices to provide adequate evidence of model fit. Moreover, Hair et al. (2019) and lacobucci (2010) recommended that the Chi Square value must be reported together with at least one absolute index (i.e., RMSEA) and one incremental index (i.e., CFI). Therefore, this study with the word of caution from Hu and Bentler (1998) where a model may still fit the data, although a couple of the fit indices presented a bad fit, selects to report the Chi-Square/df, CFI, TLI, and RMSEA.

The SPSS 25 was utilized to evaluate the adapted MCSE-RD's reliability (internal consistency) and validities (e.g., construct and external), and to calculate the descriptive statistics (percentage, skewness, kurtosis, mean, and standard deviation) of the total MCSE-RD and its three factors. Differences between gender and ethnicity were tested using independent sample t-tests. The effect sizes were interpreted according to Cohen's (1988) guideline which were small (.01), moderate (.06), and large (.14) effects. 


\section{Results}

\section{The Three-Factor Structure}

The confirmatory factor analysis (CFA) proposes links or correlations between the observed indicator variables and the underlying latent variables that they are designed to measure; then it tests them against the data to 'confirm' the proposed factorial structure (Wang \& Wang, 2012). In this procedure, CFA removes the need to summate scales and makes automatic correction of the relationships between the constructs for the amount of error variance that occurs in the measures of the construct. In this study, the CFA was performed using a hypothetical model with the three factors similar to the original version.

The original MSCE-RD was made of 22 items (Figure 1). Figure 1 showed that fit index was [ $x^{2}$ $(208)=661.383, p=.000, x^{2} / d f=3.180, C F I=.908, T L I=.897$, RMSEA $\left.=.105\right]$. None of the fit indices achieved .90 and RMSEA smaller than the cut -off point .100 (Awang et al., 2018). However, as shown in Figure 2, the results from the second order CFA model indicated that 16 items were retained because their satisfactory factor loading ranged from .78 to .93 . The other 6 items were eliminated from the construct because of the large Modification Index (MI). The resulted fit index is $\left[\mathrm{x}^{2}(103)=245.233, \mathrm{p}=.000, \mathrm{x}^{2} / \mathrm{df}=2.381, \mathrm{CFI}=.957, \mathrm{TLI}=.950\right.$, RMSEA $=.083$ ] in which all fit indices achieved .90 and RMSEA smaller than the cut -off point .100 (Awang et al., 2018). Therefore, the first hypothesized model has achieved a good overall fit as the values obtained were generally within a permissible range. 
INTERNATIONAL JOURNAL OF ACADEMIC RESEARCH IN BUSINESS AND SOCIAL SCIENCES Vol. 10 , No. 12, 2020, E-ISSN: 2222-6990 @ 2020 HRMARS

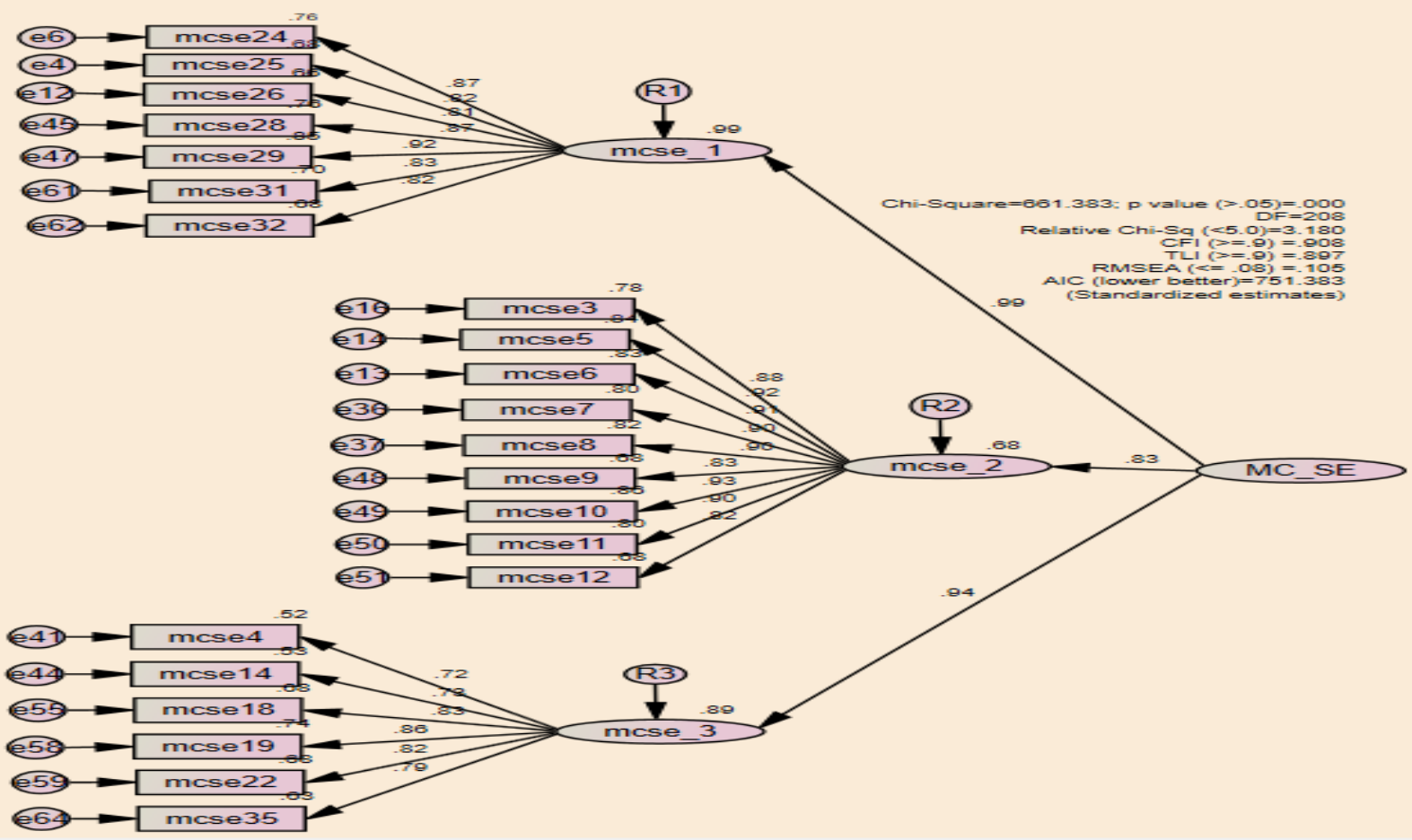

Figure 1. CFA model of original MCSE-RD for total sample Figure 2. CFA Model of revised MCSE-RD for total sample

This model tested for invariance across gender and ethnicity and it resulted in fair fit indices

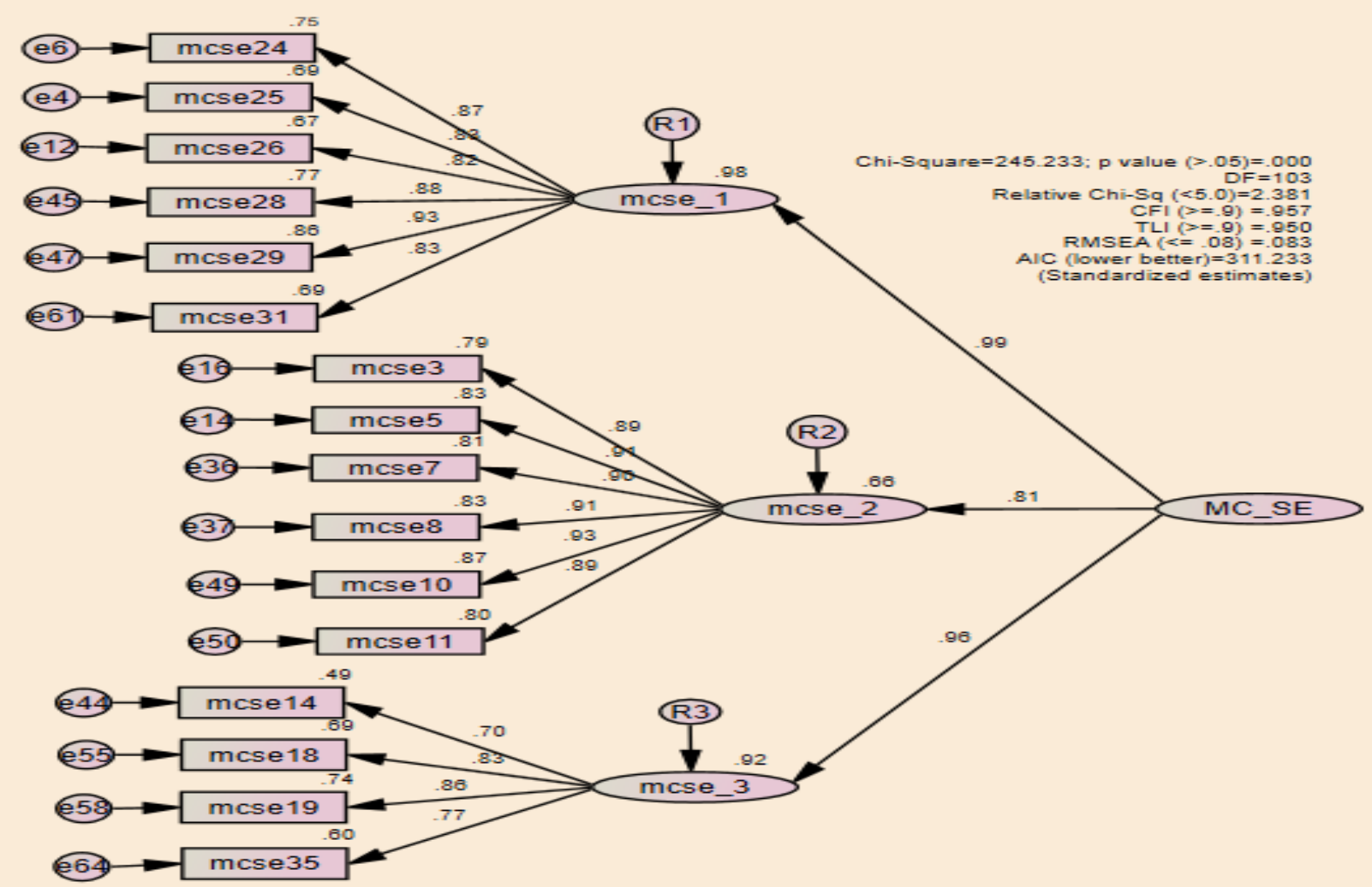

and statistically significant factor loadings. As presented in Table 3, the multigroup analysis across gender with factor loadings freely estimated resulted a good fit to the data $\left[x^{2}(202)=\right.$ 409.537, $\mathrm{p}=.000, x^{2} / \mathrm{df}=2.027, \mathrm{CFI}=.939, \mathrm{TLI}=.928, \mathrm{RMSEA}=.072 \mathrm{]}$. Similarly, the multigroup 
analysis across ethnicity with factor loadings freely estimated resulted an excellent fit to the data $\left[x^{2}(202)=416.692, p=.000, x^{2} / d f=2.063, C F I=.938, T L I=.926\right.$, RMSEA $\left.=.073\right]$.

Table 3. Fit Indices for models presented in Figure 1 and 2

\begin{tabular}{lllll}
\hline Model & Sample & CFI & TLI & RMSEA \\
\hline Model 1 & Total sample & .908 & .897 & .105 \\
Model 2 & Total sample & .957 & .950 & .083 \\
& Male subsample & .939 & .928 & .072 \\
& Female subsample & .877 & .928 & .072 \\
& Malay subsample & .938 & .926 & .073 \\
& Non-Malay subsample & .938 & .926 & .073 \\
\hline
\end{tabular}

\section{Reliability}

\section{Internal Consistency}

Finding shows that the total of Malay translated MCSE-RD instrument has excellent internal consistency with Alpha Cronbach coefficient value, $\alpha=.966$ (Table 4). Internal consistency values range from .876 to .959 that are relatively high.

Table 4. Reliability of MCSE-RD

\begin{tabular}{lll}
\hline Factor & No. of Item after CFA & Alpha Cronbach $(\alpha)$ \\
\hline 1 & 6 & .942 \\
2 & 6 & .959 \\
3 & 4 & .876 \\
Total & 16 & .966 \\
\hline
\end{tabular}

\section{Construct Reliability}

Hair et al. (2019) defines the construct reliability as the extent to which the indicator presents the measured latent construct. It is gained by computing the squared sum of factor loadings for each construct and the sum of the error variance terms for a construct. The reliability with value .70 or higher is considered as a good reliability. In this study, the MCSE-RD gains a satisfactory reliability with $\mathrm{CR}=.938$ which means it demonstrates highly significant correlation between items of the construct which indicates that the measures all consistently represent the same latent (Hair et al., 2019).

\section{Validity}

\section{Construct Validity}

Table 5 presents the corrected item-total correlation values that contributed to the construct validity that are varied from $r=.681$ to .870 . All of the 16 items were retained as Pallant (2020) maintained that items with value more than .30 should be retained. 
Table 5. Corrected Item-Total Correlation and Alpha Cronbach If Item Deleted

\begin{tabular}{cll}
\hline Item & Corrected Item-Total Correlation & Cronbach's Alpha if Item Deleted \\
\hline mcse24 & .831 & .963 \\
mcse25 & .770 & .964 \\
mcse26 & .783 & .964 \\
mcse28 & .814 & .963 \\
mcse29 & .870 & .962 \\
mcse31 & .789 & .964 \\
mcse3 & .761 & .964 \\
mcse5 & .774 & .964 \\
mcse7 & .760 & .964 \\
mcse8 & .793 & .964 \\
mcse10 & .810 & .963 \\
mcse11 & .844 & .963 \\
mcse14 & .681 & .966 \\
mcse18 & .780 & .964 \\
mcse19 & .806 & .963 \\
mcse35 & .727 & .965 \\
\hline
\end{tabular}

\section{Convergent Validity}

Hair et al. (2019) refers to convergent validity as the indicator items of a particular construct will converge or share a high proportion of the common variance. Together with construct reliability, it is also tested through the CFA. It can be measured through factor loading and Average Variance Extracted (AVE). For a measurement to be valid, the cut off value for factor loading shall be above .40 (Hair et al., 2019; Douka et al., 2009; Stevens, 2009;). However, Hair et al. (2019) also mentioned that all factors should be statistically significant with standardized loading estimates should be at least .50 or higher. The results of CFA show that factor loadings for the observed items were greater than .50 and the AVE also has met the criterion of .50 (AVE = .837). Therefore, the MCSE-RD has achieved convergent validity.

\section{Descriptive Statistics}

The mean, standard deviation, skewness, and kurtosis of item, factor and total MCSE-RD are presented in Table 6. The mean ranges from 5.320 to 6.360 and standard deviation ranges from 1.498 to 1.776. Based on the skewness and kurtosis, the items are normally distributed as the values of skewness and skewness are within \pm 2.00 and \pm 7.00 . 
Table 6. Descriptive statistics of MCSE-RD

\begin{tabular}{lllll}
\hline Item & Mean & Std. Deviation & Skewness & Kurtosis \\
\hline mcse24 & 5.835 & 1.520 & -.039 & -.692 \\
mcse25 & 5.630 & 1.669 & -.242 & .201 \\
mcse26 & 5.725 & 1.579 & -.002 & -.308 \\
mcse28 & 5.734 & 1.612 & -.076 & -.344 \\
mcse29 & 5.790 & 1.597 & .072 & -.493 \\
mcse31 & 5.714 & 1.676 & -.245 & .016 \\
mcse3 & 6.155 & 1.573 & .015 & -.812 \\
mcse5 & 6.235 & 1.514 & -.028 & -.693 \\
mcse7 & 6.360 & 1.579 & -.169 & -.748 \\
mcse8 & 6.292 & 1.526 & -.100 & -.819 \\
mcse10 & 6.300 & 1.514 & -.064 & -.877 \\
mcse11 & 6.105 & 1.498 & .036 &.- .776 \\
mcse18 & 5.560 & 1.688 & -.184 & -.175 \\
mcse19 & 5.575 & 1.643 & -.244 & -.121 \\
mcse14 & 5.480 & 1.710 & -.063 & -.289 \\
mcse35 & 5.320 & 1.776 & -.081 & -.288 \\
\hline
\end{tabular}

\section{Discussion}

This study aimed to examine the usability of multicultural counseling self-efficacy on the sample of undergraduate counselor trainees through investigation of the factor structure, reliabilities and validities of the MCSE-RD within Malaysia's cultural context. The study focused on evaluation of the hypothesized structure of MCSE-RD and on invariance of the adapted model across gender and ethnicity groups on a sample of Malaysian counselor trainees. The MCSE-RD three-factor structure was tested and confirmed through CFA on the total sample and two subsamples (e.g., gender and ethnicity). This is in line with Sheu and Lent (2007) where they found that all three factors loaded highly on the second-order factor. In addition, Sheu et al. (2012) reported the bifactor model of MCSE-RD, suggesting the existence of the three multicultural-specific factors and a generic helping skills factor.

One of the aims of this study was to determine MCSE-RD's reliability and validity for those used by undergraduate counselor trainees to accurately evaluate their confidence in counseling with multicultural clients. The result shows that the translated and adopted MCSERD has produced high internal consistency, $\alpha=.966$. Based on the coefficient values obtained, it proved that MCSE-RD has high internal consistency. This indicates that the instrument shows high consistency of the scores obtained from one administration of an instrument to another (Fraenkel et al., 2019). Other studies which adapted MCSE-RD also reported high reliability coefficient value. For instance, Sheu et al. (2012) reported $\alpha=.97$ for MCSE-RD's full-scale and range from .87 to .97 for its subscales. Meanwhile, Barden and Greene (2015) obtained $\alpha=.94$ for full-scale and range from .87 to .95 for its subscales. In addition, Rusnani and Yusoff (2017) reported $\alpha=.94$ for full-scale and range from .93 to .99 for its subscales. 
Therefore, it can be concluded that items in MCSE-RD are able to measure the intended construct and produce consistent scores (Tang et al., 2014).

Besides internal consistency, this study also investigates the construct reliability in making sure the revised MCSE-RD has stable consistency. According to Hair et al. (2019), construct reliability refers to the degree to which the construct indicators represent the latent construct. The rule of thumb of reliability estimate is $\alpha=.70$ or higher suggest good reliability and value between .60 and .70 may be acceptable. In this study, findings from CFA show that the construct reliability is high with $C R=.938$. This is in line with Hair et al. (2019) where they maintained that the existence of internal consistency is warrant by high construct reliability which also means that all items are consistently representing the same latent construct.

The mean scores for MCSE-RD subscales reflect that counselor trainees in this study have high multicultural counseling self-efficacy. This finding is however contradicted with Harun et al. (2014) which they reported of moderate mean score for MCSE-RD. This difference may be explained by the type of sample that is different in terms of professional experience and cognitive maturity. Furthermore, in this study, gender and ethnicity had no connection with MCSE-RD. These findings are supported by Barden and Greene (2015) which however, are contradicted with Sheu and Lent (2007). Sheu (2005) found men scored higher than women in his study. This is due to the probability of sample-specific outcome that may be affected by cultural or personality factors.

Validity refers to the extent to which a concept is accurately measured (Heale \& Twycross, 2015). A valid and reliable instrument is needed in order for the researcher to draw a legitimate inference. In educational and social researches, Noah (2005) stated that the most common measure of instrument validity is the construct validity. Construct validity is reflected by the corrected item-total correlation. The correlation coefficient is an indication of the degree to which each item associates with the total scores. The correlation coefficients that fit the expected pattern contribute evidence of construct validity (Kimberlin \& Winterstein, 2008). In addition, Pallant (2020) maintained that an instrument with high construct validity contains items with high values that are equal or more than .30. All of the items of the MCSE$\mathrm{RD}$ instrument have high values that are at least and more than .30 which exhibited high construct validity. High construct validity reflects the MCSE-RD's ability to measure the theoretical construct that it intends to measure.

The convergent validity refers to the indicators' items of a specific construct that converge or share a high proportion of variance in common (Hair et al., 2019). This can be measured through factor loading and Average Variance Extracted (AVE). A significant loading may still be fairly weak in strength, but standardized loading estimates with value of .50 or greater is still considered good. In addition, Douka et al. (2009) suggested that in order for a measurement to be valid, the cut off value for factor loading shall be above 40 . Another indicator for convergent validity is AVE. According to Fornell and Lacker (1981), AVE greater than 0.5 reflects high convergent validity. This requires high loadings on a factor which would indicate that they converge on some common points. As in this study, the convergent validity is .836 . This high value indicates that the model of MCSE-RD's uni-dimensionality has been obtained. 
In total, the descriptive analysis also showed that counsellor trainees believed themselves as acquiring a high level of multicultural counselling self-efficacy. This finding is consistent with studies conducted by Tucker (2017), Barden and Greene (2015), and Rigali-Oiler (2013). They also reported that counsellor trainees scored high for multicultural counselling self-efficacy. Even though the counsellor trainees were different in terms of age and level of education, the similar findings may be related to multicultural counselling course attended and counsellor trainees' stages of study. For instance, in Tucker's (2017) study, counsellor trainees were all in their early stage of graduate programme where the majority of them were between the ages of 18 to 34. In addition, most of them had attended at least one multicultural counselling course in the past five years. These characteristics may contribute to similar cognitive and affective conditions with the counsellor trainees in this study. Despite their young age and attending at least one multicultural counselling course, counsellor trainees may build up their confidence based on experience in multicultural counselling class and other university subjects related to cross-cultural or multiculturalism.

\section{Conclusion}

The stable factor structure, high reliability and validity reflect MCSE-RD's ability to measure precisely counselor trainees' confidence in working with multicultural clients. As measurement of multicultural counseling self-efficacy can enhance the outcome of study on multicultural counseling competence, this scale may contribute to the development of better framework for multicultural counseling competence. For further exploration on the MCSE-RD psychometric properties, the study may be conducted on postgraduate counselor trainees or professional counselors.

Multicultural counselling self-efficacy is based on the SET (Bandura, 1977, 1982). The findings on the psychometric properties of the adapted MCSE-RD contributed to strengthening Bandura's $(1977,1982)$ affirmation that self-efficacy needs to be measured specifically. This is because general self-efficacy was unable to reflect precisely one's confidence. Also, through the confirmed items, counsellor educator will become more convinced on maintaining the focus of the content and the teaching strategies in the multicultural counselling course. Furthermore, counsellor educator will also get ideas from the dropped items regarding aspects of content or teaching strategies that may need revision or improvisation. Besides, counsellor trainees will also gain information on their state of self-confidence in working with multicultural clients and for some, they may have an opportunity to increase theirs.

\section{Declaration}

The author (s) professed no potential circumstances with regard to the research, authorship, and/or publication of this article. Reprinted or reused by permission of the first author.

\section{Acknowledgements}

I would like to thank the original author of MCSE-RD, Dr Sheu Hung-Bin, for granting permission to use and reproduce the MCSE-RD in my doctoral research. Utmost gratitude to the Universities, faculties and counselor trainees who participated in this study.

Correspondence concerning this paper should be addressed to my co-author and the same mailing address are applicable for all the authors: 


\section{Corresponding Author}

Wan Marzuki Wan Jaafar

Department of Counselor Education \& Counseling Psychology, Faculty of Educational Studies, Universiti Putra Malaysa, 43400 UPM Serdang, Selangor Darul Ehsan, Malaysia

Email:wanmarzuki@putra.upm.edu.my

\section{References}

Awang, Z., Zainudin, N. F. S., \& Hui, L. S. (2018). Pendekatan Mudah SEM (Structural Equation Modelling). Bangi: MPWS Rich Resources Sdn. Bhd.

Bandura, A. (1977). Self -efficacy: Toward a unifying theory of behavioral change. Psychological Review, 84(2), 191-215. https://doi.org/10.1016/0146-6402(78)90002-4

Bandura, A. (1982). Self-efficacy mechanism in human agency. American Psychologist, 37(2), 122-147. https://doi.org/10.1037/0003-066X.37.2.122

Barden, S. M., \& Greene, J. H. (2015). An investigation of multicultural counseling competence and multicultural counseling self-efficacy for counselors-in-training. International Journal for the Advancement of Counselling, 37, 41-53. https://doi.org/10.1007/s10447-014-9224-1.

Bodenhorn, N., \& Skaggs, G. (2005). Development of the School Counselor Self-Efficacy Scale. Measurement and Evaluation in Counseling and Development, 38, 14-28. https://doi.org/10.1080/07481756.2005.11909766

Cohen, J. (1988). Statistical Power Analysis for the Behavioral Sciences ( $2^{\text {nd }}$ ed.). Hillsdale, NJ: Lawrence Earlbaum Associates.

Constantine, M. G., \& Ladany, N. (2001). New visions for defining and assessing multicultural counseling competence. In J. G. Ponterotto, J. M. Casas, L. A. Suzuki, \& C. M. Alexander (Eds.), Handbook of multicultural counseling (2nd Ed., pp. 482-498). Thousand Oaks, CA: Sage.

Douka, A., Harun, M. M., Jaafar, W. M. W., \& Ismail, A. (2020). Usability of Multicultural Counseling Self-Efficacy-Racial Diverse (Mcse-Rd) on The Sample of Malaysian Undergraduate Counselor Trainees. International Journal of Academic Research in Business and Social Sciences, 10(12), 597-612.

Fornell, C., \& Larcker, D. F. (1981). Structural equation models with unobservable variables and measurement error: Algebra and statistics. Journal of Marketing Research, 18, 382388. https://doi.org/ 10.2307/3150980

Fraenkel, J. R., Wallen, N. E. \& Hyun, H. H. (2019). How to Design and Evaluate Research in Education (10 ${ }^{\text {th }} \mathrm{Ed}$.). Boston: McGraw-Hill.

Harun, M. M., Kadir, R. A., \& Noah, S. M. (2014). Self-perceived multicultural counselling selfefficacy levels among school counselling teachers. Journal of Human Capital Development, 7(2), 97-114.

Hair, J.F., Babin, B.J., Anderson, R.E., \& Black, W. C. (2019). Multivariate Data Analysis (8 Ed.). Stamford, USA: Cengage Learning.

Heale, R., \& Twycross, A. (2015). Validity and reliability in quantitative studies. Evidence-Based Nursing, 18, 66-67. https://doi.org/10.1136/eb-2015-102129

Holcomb-McCoy, C., Harris, P., Hines, E. M., \& Johnston, G. (2008). School counselors' multicultural self-efficacy: A preliminary investigation. Professional School Counseling. https://doi.org/10.1177/2156759X0801100303 
Hu, L., \& Bentler, P. M. (1999). Cut off criteria for fit indexes in covariance structure analysis: Conventional criteria versus new alternatives. Structural Equation Modeling. 6(1), 1-55. https://doi.org/10.1080/10705519909540118

lacobucci, D. (2010). Structural equations modeling: Fit indices, sample size, and advanced

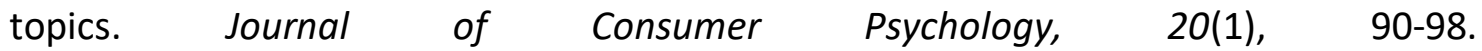
https://doi.org/10.1016/j.jcps.2009.09.003

Kimberlin, C. I., \& Winterstein, A. G. (2008). Validity and reliability of measurement instruments used in research. American Journal of Health-System Pharmacy, 65(23), 2276-2284. https://doi.org/10.2146/ajhp070364

Larson, L. M., \& Daniels, J. A. (1998). Review of the counseling self-efficacy literature. The Counseling Psychologist, 26(2), 179-218. https://doi.org/10.1177/0011000098262001

Larson, L.M., Suzuki, L.A., Gillespie, K.N., Potenza, M.T., Toulouse, A.L., \& Betchtel, M.A. (1992). Development and Validation of the Counseling Self-Estimate Inventory. Journal of Counseling Psychology, 39, 105-120. https://doi.org/10.1037/0022-0167.50.1.97

Lent, R. W., Hill, C. E., Hoffman, M. A. (2003). Development and Validation of the Counselor Activity Self-Efficacy Scales. Clinical Psychology and Psychotherapy, 12, 417-426. https://doi.org/10.1002/cpp.473

Mazila Ghazali. (2017). Influence of Wellness, Emotional Intelligence and Spiritual or SelfEfficacy toward Counsellor Trainees' Self Development. Doctoral Dissertation. Universiti Putra Malaysia.

McDonald, R. P., \& Ho, M.-H. R. (2002). Principles and practice in reporting structural equation analyses. Psychological Methods, 7, 64-82. https://doi.org/10.1037/1082-989X.7.1.64

Noah, S. M. (2005). Pengujian dan Penilaian dalam Kaunseling. Serdang: Penerbit Universiti Putra Malaysia.

Ooi Pei Boon. (2016). Relationship of Counselling Self-Efficacy, Job Satisfaction and Organizational Commitment among Malaysian School Counsellors. Doctoral Dissertation. Universiti Putra Malaysia.

Pallant, J. (2020). SPSS survival manual: A step by step guide to data analysis using IBM SPSS. London: Routledge. https://doi.org/10.4324/9781003117452

Rigali-Oiler, M. (2013). Moving Towards A Comprehensive Understanding of Multicultural Counselling Competence: The Role of Diversity Cognitive Complexity. Doctoral Dissertation, Arizona State University. Retrieve from Proquest.

Rusnani, A.K., \& Yusof, A. (2017). Reliability and validity of the Efikasi Kendiri Kaunseling Pelbagai Budaya Instrument (Translated Multicultural Counselling Self-Efficacy- Racial Diverse; MCSE-RD). Jurnal PERKAMA, 21, 97-113.

Sheu, H.-B., \& Lent, R.W. (2007). Development and initial validation of the Multicultural Counseling Self-Efficacy Scale-Racial Diversity Form. Psychotherapy: Theory, Research, Practice, Training, 44(1), 30-45. https://doi.org/10.1037/0033-3204.44.1.30.

Sheu, Hung-Bin (2005). Development and Initial Validation of the Multicultural Counselling Self-Efficacy Scale-Racial Diversity Form. Master of Arts, University of Maryland. Retrieved from Proquest on 30th January 2018.

Sheu H-B, Rigali-Oiler M, Lent RW. Multicultural Counseling Self- Efficacy Scale - Racial Diversity Form: Factor structure and test of a social cognitive model. Psychotherapy Research, 22, 527-542. https://doi.org/10.1080/10503307.2012.683344

Sipps, G. J., Sugden, G. J., \& Faiver, C. M. (1988). Counselor training level and verbal response type: Their relationship to efficacy and outcome expectations. Journal of Counseling Psychology, 35, 397-401. https://doi.org/10.1037/0022-0167.35.4.397 
Stevens, J. P. (2009). Applied multivariate statistics for the social sciences (5th ed.). Routledge/Taylor \& Francis Group.

Tang, W., Cui, Y., \& Babenko, O. (2014). Internal consistency: Do we really know what it is and how to assess it? Journal of Psychology and Behavioral Science, 2(2), 205-220. http://jpbsnet.com/journals/jpbs/Vol_2_No_2_June_2014/13.pdf

Wan Jaafar, W. M., Mohamed, O., Bakar, A. B., \& Tarmizi, R. A. (2011). Counseling self-efficacy among trainee counselor in Malaysia. Procedia-Social and Behavioral Sciences, 30, 676 - 679. https://doi.org/10.1016/j.sbspro.2011.10.130

Wang, J., \& Wang, X. (2012). Structural Equation Modeling: Applications Using Mplus. West Sussex, United Kingdom: Higher Education Press.

Tucker, S. E. (2017). Stigma of mental illness and multicultural counseling self-efficacy: investigating the implications of the multicultural training environment, mental health literacy, and empathy. Doctoral Dissertation, University of Louisville. Retrieved from Proquest.

\begin{tabular}{|l|l|}
\hline Reviewer Comments & Response \\
\hline $\begin{array}{l}\text { Researches are meant for contribution. } \\
\text { Which details theoretical and contextual } \\
\text { contribution of this research. How is it } \\
\text { significant to the existing knowledge and } \\
\text { how it play its role in context? }\end{array}$ & $\begin{array}{l}\text { The author agreed with the comment and } \\
\text { did add a paragraph after conclusion. The } \\
\text { paragraph added was such as below: }\end{array}$ \\
$\begin{array}{ll}\text { Multicultural counselling self-efficacy is } \\
\text { based on the SET (Bandura, 1977, 1982). The } \\
\text { findings on the psychometric properties of } \\
\text { the adapted MCSE-RD contributed to } \\
\text { strengthening Bandura's (1977, 1982) } \\
\text { affirmation that self-efficacy needs to be } \\
\text { measured specifically. This is because } \\
\text { general self-efficacy was unable to reflect } \\
\text { precisely one's confidence. Also, through the } \\
\text { confirmed items, counsellor educator will } \\
\text { become more convinced on maintaining the } \\
\text { focus of the content and the teaching } \\
\text { strategies in the multicultural counselling } \\
\text { course. Furthermore, counsellor educator } \\
\text { will also get ideas from the dropped items } \\
\text { regarding aspects of content or teaching } \\
\text { strategies that may need revision or } \\
\text { improvisation. Besides, counsellor trainees } \\
\text { will also gain information on their state of } \\
\text { self-confidence in working with multicultural } \\
\text { clients and for some, they may have an } \\
\text { opportunity to increase theirs. }\end{array}$ \\
\hline
\end{tabular}

